\title{
Ernst Haeckel nas coleções de Biologia aprovadas pelo PNLD 2012 - Ensino Médio
}

\author{
Ernst Haeckel in collections of Biology approved by PNLD 2012
}

\author{
MARCELO VIKTOR GILGE \\ Universidade de São Paulo | USP \\ MARIA ELICE BRZEZINSKI PRESTES \\ Universidade de São Paulo | USP
}

RESUMO Ernst Haeckel (1834-1919) foi um dos grandes nomes da ciência alemã na segunda metade do século XIX e início do século XX. Parte de sua produção científica foi devotada a defender e divulgar as ideias darwinianas de modificação das espécies. O presente artigo tem como objetivo apresentar uma análise dos livros didáticos de Biologia aprovados pelo Programa Nacional do Livro Didático (PNLD) 2012 - Ensino Médio em relação à forma como a biografia e a produção científica de Ernst Haeckel são abordadas. Visou-se entender que aspectos da produção científica do naturalista alemão eram abordados nas oito coleções aprovadas e se isso era feito de maneira historicamente adequada. Para isso, foram utilizados dois recursos metodológicos conjugados, a análise de conteúdo de Laurence Bardin e o protocolo de análise histórica de obras didáticas, proposto por Fabrício Barbosa Bittencourt. Essa análise revelou que a vida e os trabalhos de Ernst Haeckel são citados em todas as coleções aprovadas pelo PNLD 2012 - Ensino Médio, porém de maneira superficial e com incorreções de pequena monta na maioria dos casos.

Palavras-chave Ernst Haeckel - história da biologia - livro didático - PNLD.

\begin{abstract}
Ernst Haeckel (1834-1919) was one of the great names of German science in the second half of the nineteenth century and early twentieth century. Part of his scientific works was devoted to defend and promote the Darwinian ideas of modification of species. This article aims to present an analysis of textbooks of biology approved by the National Textbook Program (PNLD) 2012 on how biography and the scientific production of Ernst Haeckel are addressed. We aimed to understand which aspects of the scientific production of the German naturalist were addressed in these eight collections of textbooks, and if it was done in a historically appropriate manner. The analysis was made by using two methodological instruments, the content analysis elaborated by Bardin and the analysis protocol proposed by Fabricio Barbosa Bittencourt. This analysis revealed that the life and work of Ernst Haeckel are cited in all collections approved by PNLD 2012, however superficially and with minor inaccuracies in most cases.
\end{abstract}

Keywords Ernst Haeckel - history of biology - textbooks - PNLD. 


\section{Introdução}

Ernst Heinrich Phillipp August Haeckel (1834-1919) foi um dos grandes nomes da ciência europeia durante a segunda metade do século XIX e o começo do século XX. A repercussão de suas obras, especialmente as destinadas a divulgar as ideias de Darwin, transformaram Haeckel num dos nomes mais importantes na defesa da teoria evolutiva, a ponto de receber a alcunha de "Darwin alemão"1.

Sendo Haeckel um personagem notório na História da Ciência, imaginamos que sua presença em obras didáticas de Biologia voltadas ao ensino básico seria comum. Essa percepção prévia acabou se confirmando no desenvolvimento deste trabalho. Por outro lado, uma busca por trabalhos acadêmicos na área da História da Ciência e Ensino que analisassem a presença de Ernst Haeckel em livros didáticos brasileiros indicou a inexistência desse tipo de produção.

0 objetivo deste trabalho é apresentar uma análise dos livros didáticos de Biologia aprovados pelo Programa Nacional do Livro Didático (PNLD) 2012 - Ensino Médio em relação à forma como a biografia e a produção científica de Ernst Haeckel são abordadas. Visou-se entender que aspectos da produção científica do naturalista alemão eram citados nesses livros, e se isso era feito de maneira historicamente adequada. Para isso, foi elaborado, previamente, um panorama das principais contribuições de Haeckel, destacando aspectos relevantes de sua vida e obra.

\section{Ernst Haeckel}

Ernst Haeckel (1834-1919) nasceu em 16 de fevereiro de 1834 em Potsdam, na Alemanha, e foi criado em Merseburg, no mesmo país². Ele faleceu em 9 de agosto de 1919, aos 85 anos, na cidade alemã de Jena.

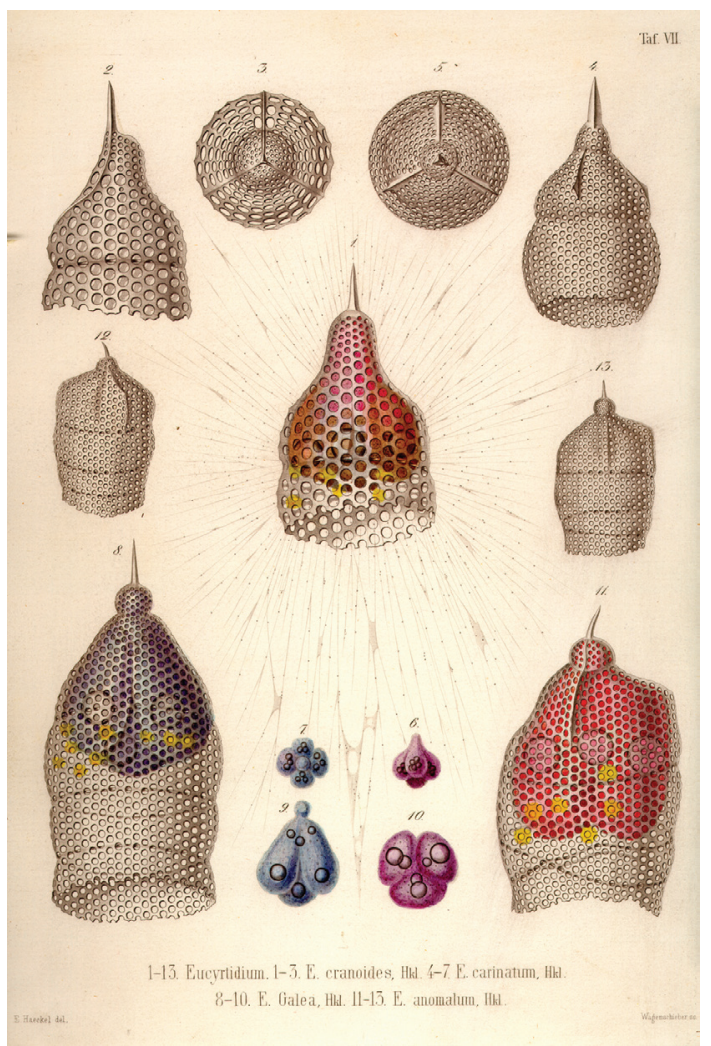

Figura 1. Prancha número 7 da monografia Die Radiolarien, publicada em 1862.
Haeckel iniciou seus estudos de grau superior ao ingressar, em 1852, na Universidade de Würzburg (Alemanha), onde cursou Medicina ${ }^{3}$. 0 ingresso no curso deveu-se a uma imposição paterna, uma vez que a grande paixão de Haeckel era o estudo da natureza, da qual ele possuía uma visão derivada do Romantismo de Johann Wolfgang von Goethe (1749-1832) e Alexander von Humboldt (1769-1859).

Seu maior interesse era por botânica, graças a suas leituras dos trabalhos de Mathias Schleiden ${ }^{4}$. Assim, ao longo de todo 0 curso, Haeckel lutou contra sua aversão ${ }^{5}$ pela prática médica ${ }^{6}$. Por outro lado, ele entendia que os conhecimentos adquiridos no curso poderiam ser úteis em seu futuro como naturalista, como ele afirmou em uma carta para seus pais: “Eu, portanto, considero a anatomia de um ponto de vista puramente natural e histórico [não médico], como a história natural da humanidade e, como tal, talvez venha a ser útil novamente quando eu posteriormente estudar matemática e ciências naturais"7.

Durante seu período como estudante universitário, Haeckel teve contato com nomes importantes do meio acadêmico alemão, como Albert von Kölliker (1817-1905), Johannes Müller (18011858), Franz Leydig (1821-1908), Carl Gegenbaur (1826-1903) e Rudolf Virchow (1821-1902) ${ }^{8}$. A relação de Haeckel com esses cientistas contribuiu para os rumos que ele seguiu em sua carreira. 
Fig. 5 ,

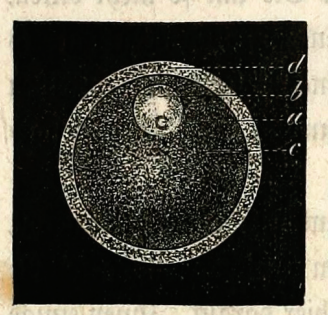

Fig. 6.

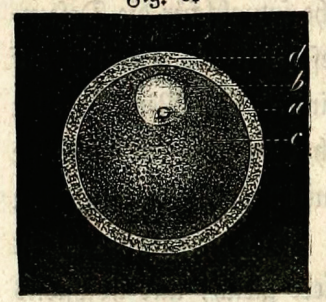

Fig. 7.

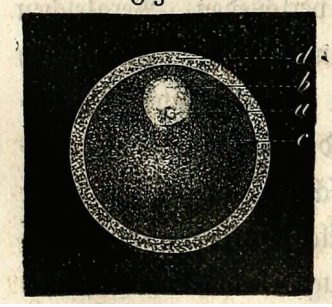

Figura 2. Ilustração

comparando óvulos de homem (5), macaco (6) e cão

(7), extraída do Natürliche

Schöpfungsgeschichte.

Mesmo com a convicção de que não exerceria a profissão, Haeckel diplomou-se em Medicina em março de 1857. Porém, desde antes de se graduar Haeckel já dirigia seus caminhos para a atividade de naturalista. Isso se consolidou em 1861, quando passou a trabalhar na Universidade de Jena, onde ficaria até sua aposentadoria em $1909^{9}$.

Como naturalista, Haeckel foi bastante ativo. Envolveu-se em diversas expedições, e descreveu cerca de quatro mil novas espécies de protozoários e animais ${ }^{10}$. Sua especialidade era a zoologia marinha, tendo desenvolvido trabalhos sobre esponjas calcárias, sifonóforos, cnidários e radiolários. Este grupo de protozoários foi o objeto de estudo de sua monografia Die Radiolarien. [Rhizopoda Radiaria] Eine Monographie (Os radiolários. [Rhizopoda Radiaria]. Uma monografia, 1862), em que são encontradas ilustrações produzidas pelo próprio Haeckel que chamam a atenção pelo nível de detalhamento (Figura 1).

Em 1860, Haeckel iniciou a leitura da tradução para o alemão, realizada por Heinrich Georg Bronn (1800-1862), de A Origem das Espécies ${ }^{11}$. A partir de então ele se tornou um grande defensor das ideias de Darwin, e seus trabalhos, especialmente na área da morfologia, passaram a ser fundamentados nessas ideias ${ }^{12}$.

0 alcance de sua produção científica fez com que Haeckel passasse a ser considerado, ainda em sua época, como um dos principais defensores da teoria evolutiva proposta por Charles Darwin. Historiadores como Robert J. Richards defendem que os escritos de Haeckel foram mais determinantes para popularizar as ideias darwinianas do que as próprias obras de Darwin ${ }^{13}$.

Chama a atenção também sua propensão para desenvolver neologismos. Ao criar novas palavras, Haeckel fornecia denominações para os conceitos que procurava explicar. Entre os termos criados por ele que são usados ainda hoje nas Ciências Biológicas podemos citar: "ecologia", "gastrulação", "monera", "protista", "filogenia" e "ontogenia".

No entanto, a notoriedade de Haeckel também foi construída a partir de eventos controversos. Ao longo de sua carreira ele sofreu diversas acusações de fraude e plágio, como nos mostram os trabalhos de J. David Archibald ${ }^{14}$ e Robert J. Richards ${ }^{15}$. Na primeira edição de sua obra Natürliche Schöpfungsgeschichte (História natural da criação) ${ }^{16}$, por exemplo, Haeckel pretendeu ilustrar as semelhanças encontradas entre animais de diferentes espécies nos estágios iniciais de seu desenvolvimento.

Para isso, ele apresentou dois conjuntos de ilustrações: no primeiro encontram-se três óvulos que Haeckel identificava como sendo de ser humano, macaco e cão (Figura 2). 0 segundo conjunto mostra embriões de cão, galinha e tartaruga em um estágio que Haeckel chamou de "forma de violino" (Geigenförmige), que podem ser vistos na Figura 3.

Tanto as imagens de óvulos quanto as dos embriões em "forma de violino" são claramente três reproduções da mesma figura. Não tardou para que contemporâneos de Haeckel apontassem 0 problema. Louis Agassiz (1807-1873), o notório antidarwinista do século XIX, ao denunciar a reprodução tripla da mesma imagem nos dois casos citados, exclamou que isso era "abominável!"17. Em relação a essa acusação de fraude, Haeckel reconheceu que realmente havia reproduzido três vezes a mesma ilustração, e classificou como "bobagem extrema" sua atitude ${ }^{18}$.

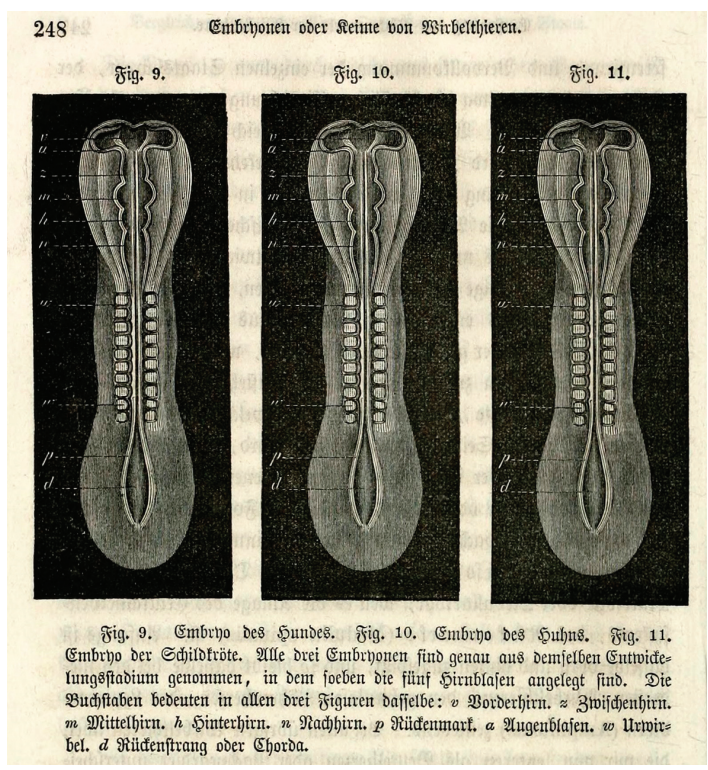

Figura 3. Comparação entre embriões de cão, galinha e tartaruga na primeira edição do Natürliche Schöpfungsgeschichte. 
Haeckel também desenvolveu trabalhos em filosofia e foi um militante anticlerical. 0 monismo e a biologia eram, para ele, os substitutos para as chamadas religiões reveladas ${ }^{19}$, das quais ele foi um combatente ferrenho.

Assim como ocorreu com Darwin, o nome de Haeckel foi envolvido com a ascensão do nazismo e suas ideias de superioridade racial. Edward Larson, por exemplo, acredita que seguidores de Haeckel aplicaram conceitos de eugenia em campos de concentração nazistas ${ }^{20}$. Robert J. Richards indica que seguidores de Hitler claramente procuraram associar Haeckel às propostas higienistas defendidas pelos nazistas. Heinz Brücher chegou a traçar a árvore genealógica da família de Haeckel para demonstrar sua "pureza" e, consequentemente, a validade de aceitar suas ideias²1.

0 impacto das obras de Haeckel também foi percebido no Brasil. Ele era um dos autores lidos nas comunidades alemãs por volta de 1870, e depois nas italianas. Em 1875 cerca de 80\% dos descendentes de alemães nascidos no Brasil acreditavam no monismo22. Olaf Breidbach, na obra Visions of nature - the art and science of Ernst Haeckel (Visões da natureza - a arte e a ciência de Ernst Haeckel, 2006), destaca que a História da Literatura Brasileira, de Sílvio Romero, faz menção a Haeckel como tendo influenciado a literatura brasileira entre o final do século XVIII e o final do século XIX. Segundo Romero, o período compreendido entre 1870 e 1899 poderia ser descrito como a "bifurcação haeckeliana no evolucionismo"23.

\section{O livro didático de Biologia e o PNLD}

A utilização da História da Ciência em projetos pedagógicos tem se tornado cada vez mais frequente, com um consequente aumento de pesquisas na área. Como exemplo podem ser citados os diversos estudos que têm sido feitos a respeito da utilização da História da Ciência em livros didáticos de Biologia, tais como os de Lilian Al-Chueyr Pereira Martins $^{24}$, Maria Helena da Silva Carneiro Carneiro \& Maria Luiza Gastal ${ }^{25}$, Sandra Regina Gimenez Rosa \& Marcos Rodrigues Silva ${ }^{26}$ e Fabrício Barbosa Bittencourt ${ }^{27}$.

A História da Ciência pode ser utilizada como instrumento para a superação de estratégias ultrapassadas de ensino-aprendizagem. Como afirma Ana Maria Alfonso-Goldfarb: “0 estudo da gênese das ideias científicas também ajuda a que se entenda melhor seus processos e convenções, evitando a velha técnica escolar de aprender de cor"28.

Michael Matthews observa que estudar a vida e a época em que viveram os personagens da Ciência "humaniza a matéria científica, tornando-a menos abstrata e mais interessante aos alunos"29. Além disso, a aplicação da História da Ciência em processos pedagógicos permite que a forma como os cientistas conduzem suas pesquisas seja apresentada de maneira mais próxima da realidade ${ }^{30}$.

Porém, é comum que os relatos históricos sejam abordados de forma inadequada, apresentando erros factuais ou deficiências de contextualização. Essas deficiências podem gerar uma visão equivocada não só da Ciência, como da vida dos personagens históricos envolvidos com o processo científico ${ }^{31}$.

Espera-se que os livros didáticos das áreas de Ciências abordem a construção do conhecimento da forma mais fiel possível aos eventos históricos, para que os estudantes tenham uma noção mais adequada da natureza da Ciência ${ }^{32}$. Em outras palavras, é importante que a utilização da História da Ciência nos materiais didáticos promova a reflexão sobre o processo de construção do conhecimento científico. Reduzir o uso da ferramenta histórica a uma mera glorificação dos personagens históricos, listas de datas e citações de descobertas ou invenções pode gerar uma visão equivocada da Ciência ${ }^{33}$.

Porém, como observam Rosa \& Silva, “o conteúdo histórico dos livros nem sempre favorece a reflexão, assim como nem sempre estimula a capacidade investigativa do aluno, pois se concentra na exposição de datas e fatos, negligenciando assim o processo de contextualização da história" ${ }^{\prime 34}$.

Quanto aos documentos oficiais produzidos pelo Ministério da Educação, percebe-se que a História da Ciência é mencionada, mas sua importância recebe pequeno destaque. Entre as raras menções, encontra-se nos Parâmetros 
Curriculares Nacionais (PCN) a seguinte passagem: "elementos da história e da filosofia da Biologia tornam possível aos alunos a compreensão de que há uma ampla rede de relações entre a produção científica e o contexto social, econômico e político. É possível verificar que a formulação, o sucesso ou o fracasso das diferentes teorias científicas estão associados a seu momento histórico"35. 0 problema maior reside em que essa recomendação não é acompanhada de uma discussão mais detalhada sobre quanto, como e quando introduzir a História da Ciência no ensino. Também não é indicado de que modo o professor pode se preparar e onde pode obter materiais para trabalhar aspectos históricos com seus alunos.

Atualmente, a avaliação e a distribuição gratuita de obras didáticas para escolas públicas são feitas pelo Programa Nacional do Livro Didático (PNLD), conduzido pelo governo federal. 0 PNLD garante a distribuição gratuita de livros didáticos, paradidáticos e dicionários para escolas públicas de todo o território nacional. Assim, cumpre-se o determinado na Lei de Diretrizes e Bases, de 20 de dezembro de 1996, que estabelece em seu artigo 4º , item VIII:

Art. $4^{\circ}$. O dever do Estado com a educação escolar pública será efetivado mediante a garantia de:

VIII - atendimento ao educando, no ensino fundamental público, por meio de programas suplementares de material didático-escolar, transporte, alimentação e assistência à saúde ${ }^{36}$

0 PNLD visa fornecer aos estudantes das escolas públicas de todo o país, de forma gratuita, obras didáticas que passaram por avaliações que atestam sua adequação a critérios pré-estabelecidos pelo Fundo Nacional para o Desenvolvimento da Educação (FNDE) do MEC. A primeira distribuição de obras de Biologia para o Ensino Médio ocorreu no PNLD 2007, e em 2009 ocorreu a segunda distribuição de livros da área. Para o edital 2012, dezesseis coleções foram inscritas, das quais oito foram aprovadas.

0 processo de seleção do PNLD 2012 - Ensino Médio teve início em 4 de dezembro de 2009, com a publicação do Edital de convocação para inscrição no processo de avaliação e seleção de obras didáticas para o Programa Nacional do Livro Didático PNLD 2012 - Ensino Médio.

Após adequar suas coleções aos critérios estabelecidos no edital, as editoras concorrentes puderam inscrever suas coleções no período correspondente entre 10 de maio de 2010 e 14 de maio de 2010. Seguiu-se então o processo de avaliação, que ocorreu durante o restante do ano de 2010, conduzido por uma equipe de avaliação escolhida pelo MEC.

Em 2011 foi divulgado o Guia de Livros Didáticos PNLD 2012 - Biologia ${ }^{37}$. Neste guia são apresentadas as oito coleções que foram consideradas como mais adequadas para auxiliar os professores no processo de ensino de Biologia no Ensino Médio.

As coleções aprovadas foram as seguintes ${ }^{38}$ :

- LD 1: BIO. Sérgio Rosso \& Sônia Lopes. Ed. Saraiva ${ }^{39}$;

- LD 2: Biologia. César, Sezar \& Caldini. Ed. Saraiva ${ }^{40}$;

- LD 3: Biologia. Pezzi, Gowdak \& Mattos. Ed. FTD41;

- LD 4: Biologia para a nova geração. V. Mendonça \& J. Laurence. Ed. Nova Geração42;

- LD 5: Biologia. Gilberto Rodrigues Martho \& José Mariano Amabis. Ed. Moderna43;

- LD 6: Biologia Hoje. Fernando Gewandsnajder \& Sérgio de Vasconcellos Linhares. Ed. Ática44;

- LD 7: Novas bases da Biologia. Nélio Bizzo. Ed. Ática45;

- LD 8: Ser protagonista Biologia. André Catani et al. Edições SM ${ }^{46}$

Nesta pesquisa, essas obras foram utilizadas para se realizar uma análise do conteúdo histórico relacionado a Ernst Haeckel. Veremos agora de que forma essa análise foi efetuada. 


\section{Análise das menções a Ernst Haeckel nas coleções aprovadas}

Para realizar a análise das coleções didáticas de Biologia aprovadas pelo PNLD - Ensino Médio 2012 foram utilizados dois recursos metodológicos conjugados, a análise de conteúdo de Laurence Bardin ${ }^{47}$ e 0 protocolo de análise histórica de obras didáticas, proposto por Bittencourt ${ }^{48}$.

A "análise de conteúdo" proposta por Laurence Bardin é constituída de três fases de análise: pré-análise; exploração do material; e tratamento dos resultados e interpretação. A pré-análise tem por objetivo "tornar operacionais e sistematizar as ideias iniciais"49. Nessa fase devem ser realizadas a escolha dos documentos a serem analisados e a formulação de hipóteses e objetivos. A segunda fase, de exploração do material, é caracterizada como "a aplicação sistemática das decisões tomadas" ${ }^{\prime \prime 0}$ na fase de pré-análise. Finalmente, a terceira fase, tratamento dos resultados e interpretação, é descrita por Bardin como a etapa em que ferramentas de análise de dados, como estatísticas ou de análise fatorial, são utilizadas. No entanto, para o presente trabalho foi necessária uma adaptação desta etapa, uma vez que a intenção era confrontar os textos das coleções didáticas com fontes primárias e secundárias.

Como orientação para essa adaptação, seguimos parcialmente o protocolo de análise histórica de obras didáticas, proposto por Bittencourt, que elaborou as seguintes categorias de análise ${ }^{51}$ : contexto epistêmico, contextualização histórica do episódio, vida dos personagens, características dos personagens considerados centrais, comunidade dos estudiosos, abordagem das ideias e desenvolvimento da Ciência ${ }^{52}$.

Baseando-se livremente nessas categorias propostas por Bittencourt, elaboramos as categorias de análise dos livros didáticos previstas para ocorrer na etapa de tratamento de dados e interpretação, de acordo com a análise de conteúdo de Bardin.

Portanto, as três etapas de desenvolvimento dessa parte do trabalho podem ser assim descritas:

A) Pré-análise: pesquisa preliminar para a escolha do material didático a ser analisado. Essa escolha, como já indicado, recaiu sobre as coleções aprovadas pelo PNLD-2012 Ensino Médio. Após a escolha determinou-se a hipótese de que o tratamento dado aos trabalhos de Ernst Haeckel nos livros didáticos de Biologia que seriam analisados apresentariam problemas quanto à abordagem histórica. Essa hipótese foi fundamentada a partir da leitura de trabalhos sobre obras didáticas que indicavam a ocorrência frequente desses problemas em livros didáticos, tais como os de Carneiro \& Gastal ${ }^{53}$ e Martins $^{54}$;

B) Exploração do material: leitura integral - incluindo os Manuais do Professor - das oito coleções aprovadas pelo processo de seleção do MEC e indicadas no Guia PNLD 2012. Durante a leitura dos livros didáticos aprovados foram identificadas e registradas todas as passagens em que o nome de Ernst Haeckel foi citado, bem como elementos gráficos, como ilustrações ou fotos, que tivessem relação com o cientista alemão;

C) Tratamento dos resultados e interpretação: após a coleta dos dados, realizou-se uma categorização desses dados com base na técnica denominada por Bardin como "por acervo"55. Essa técnica implica em uma criação de categorias a posteriori, ou seja, após a leitura do material a ser analisado.

Assim, utilizando-se a técnica de categorização "por acervo" proposta por Bardin, nove categorias de classificação para as referências a Haeckel nas coleções analisadas foram criadas:

- Dados biográficos básicos: dados pessoais, como datas de nascimento e morte, locais de nascimento e morte, relações de parentesco e locais de atividade profissional;

- Contexto histórico: passagens que situam Haeckel no momento histórico-científico em que ele esteve inserido;

- Registro fotográfico: fotografias de Ernst Haeckel ou que mostrassem situações relacionadas a Haeckel, como estabelecimentos em que trabalhou, locais de coleta de materiais etc;

- llustrações: ilustrações produzidas por Ernst Haeckel e publicadas em suas obras; 
- Propositor do termo Protista: passagens em que Haeckel é identificado como criador desse termo;

- Propositor do termo Monera: passagens em que Haeckel é identificado como criador desse termo;

- Propositor do termo Ecologia: passagens em que Haeckel é identificado como criador desse termo;

- LBF: passagens em que a Lei Biogenética Fundamental é mencionada e associada a Ernst Haeckel;

- Árvores da vida: passagens em que as árvores filogenéticas (stämmbaums) propostas por Ernst Haeckel são mencionadas.

\section{Resultados}

A tabela 1 mostra os resultados obtidos durante a análise das coleções selecionadas pelo PNLD 2012 - Ensino Médio. Alguns dos dados observados na tabela chamam a atenção. Percebe-se que o nome de Ernst Haeckel foi citado nas oito coleções aprovadas pelo PNLD - Ensino Médio 2012, sendo que em todas elas estão presentes os dados biográficos básicos, e apenas a coleção LD 2 não insere Haeckel em um contexto histórico. A coleção LD 1 é a única que contempla todas as categorias criadas para essa análise.

Tabela 1. Resultados obtidos durante a análise das coleções selecionadas pelo PNLD 2012 - Ensino Médio.

\begin{tabular}{l|c|c|c|c|c|c|c|c} 
& LD1 & LD2 & LD3 & LD4 & LD5 & LD6 & LD7 & LD8 \\
\hline Dados biográficos básicos & $\mathrm{X}$ & $\mathrm{X}$ & $\mathrm{X}$ & $\mathrm{X}$ & $\mathrm{X}$ & $\mathrm{X}$ & $\mathrm{X}$ & $\mathrm{X}$ \\
\hline Contexto histórico & $\mathrm{X}$ & & $\mathrm{X}$ & $\mathrm{X}$ & $\mathrm{X}$ & $\mathrm{X}$ & $\mathrm{X}$ & $\mathrm{X}$ \\
\hline Registro fotográfico & $\mathrm{X}$ & & & & & & $\mathrm{X}$ & $\mathrm{X}$ \\
\hline llustrações & $\mathrm{X}$ & & & & $\mathrm{X}$ & & & $\mathrm{X}$ \\
\hline Criador do termo Protista & $\mathrm{X}$ & $\mathrm{X}$ & $\mathrm{X}$ & & $\mathrm{X}$ & & $\mathrm{X}$ & $\mathrm{X}$ \\
\hline Criador do termo Monera & $\mathrm{X}$ & & & & & & $\mathrm{X}$ & $\mathrm{X}$ \\
\hline Criador do termo Ecologia & $\mathrm{X}$ & & & & & & & \\
\hline LBF & $\mathrm{X}$ & & & $\mathrm{X}$ & & $\mathrm{X}$ & & \\
\hline Árvores da vida & $\mathrm{X}$ & & & $\mathrm{X}$ & $\mathrm{X}$ & & & \\
\hline
\end{tabular}

Outros dados coletados que não estão inseridos na tabela: nos manuais do professor, citações a Haeckel foram identificadas nas coleções LD 6 (v. 3) e LD 7 (v. 1 e 2). 0 nome de Haeckel aparece em atividades na coleção LD 1 (v. 3) e na coleção LD 4 (v. 3). Nas coleções LD 1 (v. 3) e LD 3 (v. 3) são citadas obras de Haeckel nas referências bibliográficas.

Analisando as informações históricas a respeito de Haeckel presentes nessas coleções, podemos dizer que em geral elas mostram poucos equívocos. 0 erro mais comum encontrado nessas obras é 0 da datação equivocada de proposições feitas por Haeckel - este erro foi detectado em cinco passagens ao longo das oito coleções. Na coleção LD1, por exemplo, encontramos no v. 1, p. 32 a seguinte passagem:

A palavra Ecologia deriva de duas palavras gregas: oikós (casa) e logos (estudo). Assim, Ecologia significa literalmente o 'estudo da casa'. Essa palavra foi usada pela primeira vez em 1870 pelo biólogo alemão Ernst Haeckel, para designar o estudo das interações dos organismos entre si e com os demais componentes do ambiente. ${ }^{56}$

Na verdade, o termo "oecologie", que foi traduzido para o português como "ecologia", foi cunhado por Haeckel na obra Generelle Morphologie der Organismen, de 1866. 0 trecho que apresenta o termo é uma nota de rodapé: 
Ao ampliar o conceito de Biologia neste amplo e compreensível escopo, nós encerramos o estreito e limitado senso em que frequentemente (especiamente na entomologia) se confunde a Biologia com a Ecologia, [...] com o modo que os organismos se relacionam entre si e com o meio externo etc..$^{57}$

A passagem mais controversa foi encontrada na coleção LD4, v. 3, p. 233:

Assim, de acordo com Haeckel, durante o desenvolvimento embrionário o indivíduo passaria por fases que representavam estágios de seus antepassados adultos. Isso de fato não ocorre. O que realmente ocorre é certa semelhança entre os estágios iniciais do desenvolvimento embrionário, semelhança essa tanto maior quanto mais próximas estejam as espécies, do ponto de vista evolutivo. Essa ideia mais correta foi proposta inicialmente por Von Baer, naturalista que viveu entre 1792 e 1876.

Ernest Heinrich Philipp August Haeckel foi um naturalista alemão nascido em 1834 e falecido em 1919. Haeckel estudou medicina em Berlim e Viena, mas, influenciado por Charles Darwin, deixou a medicina para se dedicar ao estudo da anatomia e se tornou professor de zoologia. Fez numerosas expedições para estudo de diversos animais e protozoários.

Haeckel foi o primeiro a propor uma árvore genealógica para os animais. Haeckel foi grande defensor da teoria da evolução, ficando conhecido como o 'Darwin alemão'. ${ }^{58}$

A passagem anterior apresenta algumas afirmações que merecem ser discutidas mais cuidadosamente. Em primeiro lugar, Haeckel realmente desenvolveu parte de seus estudos de medicina em Berlim e Viena. Porém, grande parte do curso foi desenvolvida em Würzburg, o que não é informado na passagem. Em seguida, podemos discutir a afirmação de que Haeckel "deixou a medicina". Afinal, ele nunca exerceu a profissão médica, mas concluiu o curso em 1857. Além disso,

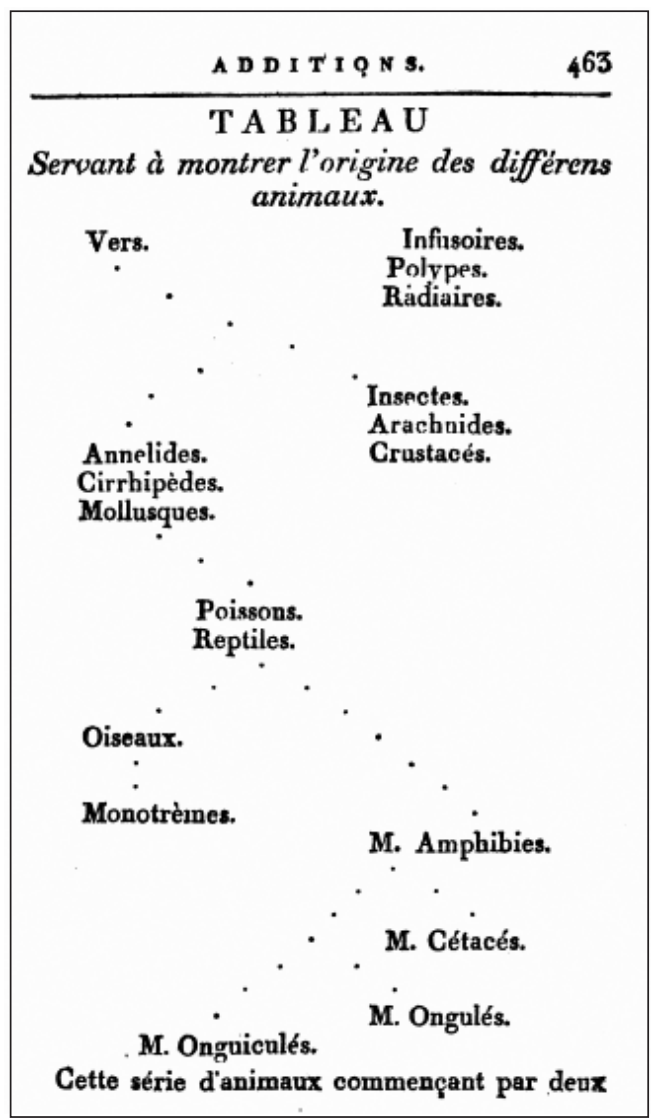

Figura 4. Esquema filogenético esboçado por Lamarck para sua obra Philosophie Zoologique.
Haeckel iniciou a leitura de $A$ origem das espécies em 1860, três anos após a conclusão do curso de medicina. Portanto, não parece fazer sentido a afirmação de que a influência de Darwin teria levado ao abandono da medicina por Haeckel.

A passagem afirma ainda que Haeckel abandonou a medicina para estudar anatomia. Ora, já durante o curso de medicina Haeckel passou a se dedicar a estudos de anatomia, que contribuíram decisivamente para seus trabalhos posteriores em Zoologia. Seu trabalho de conclusão de curso, inclusive, versava sobre tecidos de crustáceos ${ }^{59}$.

Haeckel defendeu a teoria evolutiva darwiniana com bastante empenho, dedicando grande parte de sua produção científica e literária a esse propósito e, como indicado na Introdução desta dissertação, passou a ser conhecido como o "Darwin alemão". Porém, a afirmação sobre a proposição das árvores genealógicas para animais pode ser contestada. Se considerarmos as árvores genealógicas como esquemas que indicam relações filogenéticas, não necessariamente utilizando uma figura de árvore, encontraremos evidências para essa contestação nos trabalhos de Jean Baptiste Lamarck e St. George Mivart. Em 1809, no seu Philosophie Zoologique, Lamarck inseriu uma ilustração que pode ser considerada uma árvore genealógica (Figura 4). Esse diagrama apresenta possíveis relações genealógicas entre grupos animais.

Já em 1865, um ano antes da publicação do Generelle Morphologie, obra em que Haeckel apresenta suas "árvores da vida", 
Mivart publicou uma árvore genealógica de primatas (Figura 5). Assim, pode-se reafirmar que a indicação de Haeckel como primeiro a propor uma árvore genealógica para animais é passível de discussão.

\section{Considerações finais}

A análise das coleções de Biologia aprovadas pelo PNLD 2012 - Ensino Médio revelou que, em todas elas, o nome do naturalista alemão Ernst Haeckel é mencionado, ainda que na maioria dos casos seus trabalhos sejam abordados de forma superficial. Também foi observada a existência de incorreções históricas presentes nessas coleções.

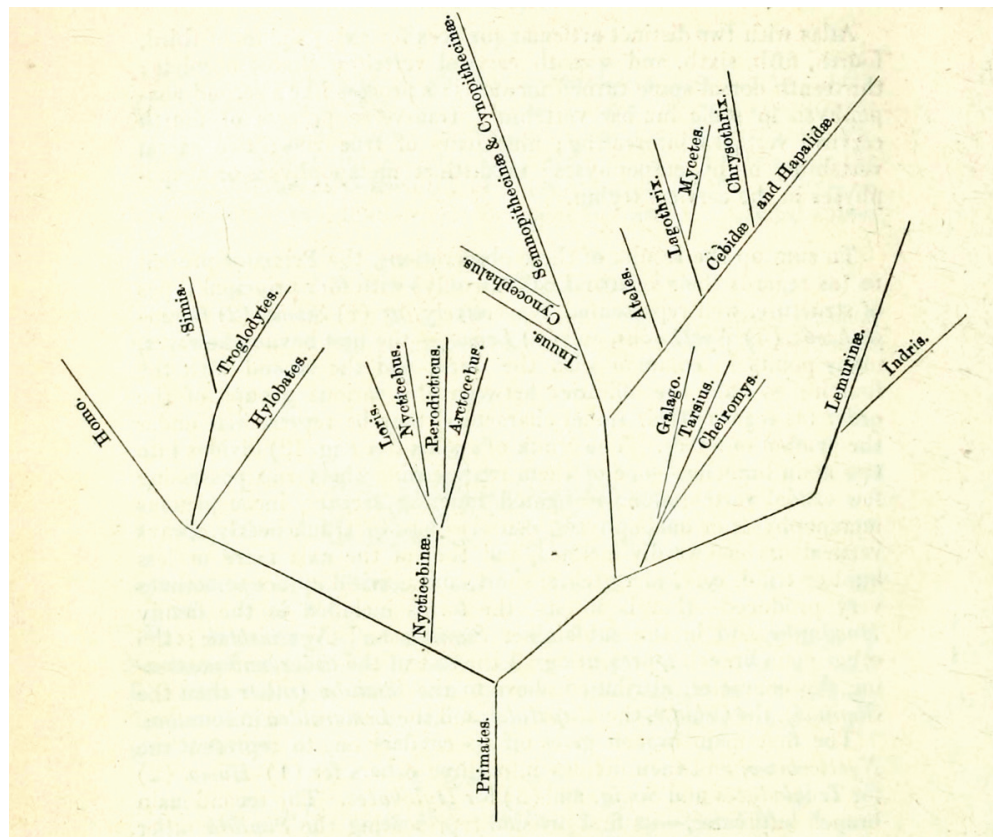

Figura 5. Esquema filogenético para primatas esboçado por St. George Mivart. Esses erros foram de pequena monta, o que é positivo. Contudo, a análise também mostrou que a referência contextual, isto é, associação de Haeckel com o momento histórico e científico no qual vivia, é pouco desenvolvida. Além disso, passagens importantes da vida de Haeckel, como a utilização de figuras de embriões para ilustrar a Lei Biogenética Fundamental, bem como as acusações de fraude e plágio que elas geraram, ou mesmo a associação de suas ideias com a ascensão do nazismo são raramente exploradas.

Erros como imprecisões nas datações obviamente podem ser considerados problemas menores, que não interferem decisivamente no processo de ensino-aprendizagem. Porém, o fato de erros menores não serem detectados pelos avaliadores ou pelos editores dessas obras didáticas permite inferir que, circunstancialmente, erros mais importantes também não o sejam. Essa é uma questão relevante, pois descrições imprecisas de eventos históricos podem interferir na compreensão do processo de construção do conhecimento científico por parte dos estudantes.

Imperfeições em obras didáticas sempre podem estar presentes, seja de ordem autoral ou editorial. A intenção deste trabalho não é criticar, substituir ou complementar o trabalho dos avaliadores indicados pelo MEC, e sim colaborar para 0 entendimento de que as informações históricas merecem tanto cuidado na avaliação quanto outros aspectos. Afinal, de acordo com o Ministério da Educação, a "correção e atualização de conceitos, informações e procedimentos" ${ }^{60}$ são dois dos critérios que os avaliadores das coleções devem levar em consideração em suas análises.

Entre os critérios de avaliação utilizados pelos avaliadores do PNLD, o que mais se aproxima de uma avaliação do conteúdo histórico é o que solicita que 0 avaliador verifique se a obra "auxilia na construção de uma visão de que 0 conhecimento biológico e as teorias em Biologia se constituem em modelos explicativos, elaborados em determinados contextos sociais e culturais, superando a visão a-histórica de que a vida se estabelece como uma articulação mecânica de partes" ${ }^{\prime \prime 1}$. Percebe-se, no trecho, que a associação com a História da Ciência não é direta, explícita, mas apenas implícita, tornando difícil que os avaliadores se preocupem com uma análise detalhada e rigorosa desse componente. Afinal, a que "visão a-histórica" os elaboradores desse critério se referem? Seria recomendável que fossem oferecidos critérios objetivos e explícitos, a exemplo dos sugeridos por Laurinda Leite ${ }^{62}$.

Assim, acreditamos que a própria concepção dos critérios de avaliação em relação à Historia da Ciência merece um tratamento mais adequado, de forma a ressaltar a importância dessa área do conhecimento e facilitar o trabalho dos avaliadores. 
Dessa forma, sugerimos que as equipes de avaliadores das coleções inscritas no PNLD tenham, entre seus componentes, especialistas em História da Ciência, de forma a diminuir a chance de que imprecisões nessas áreas estejam presentes nas obras aprovadas.

Essa mesma providência poderia ser tomada pelas editoras que inscrevem as obras didáticas nos processos de seleção do PNLD, uma vez que nem sempre os leitores técnicos que revisam as coleções são especialistas em História da Ciência.

\section{Notas e referências bibliográficas}

Marcelo Viktor Gilge é mestre em Genética e Biologia Evolutiva pelo Instituto de Biociências da Universidade de São Paulo. E-mail: mgilge@ib.usp.br.

Maria Elice Brzezinski Prestes é professora do Instituto de Biociências da Universidade de São Paulo. E-mail: eprestes@ib.usp.br.

REYNOLDS, A. Ernst Haeckel and the Theory of the Cell State: Remarks on the History of a Bio-political Metaphor. History of Science, v. 46, n. 2, p. 123-152, 2008.

2 BREIDBACH, 0. Visions of nature: the art and science of Ernst Haeckel. Munique: Prestel, 2006, p. 77.

3 RICHARDS, R. J. The tragic sense of life: Ernst Haeckel and the struggle over evolutionary thought. Chicago: The University of Chicago Press, 2008. p. 27.

4 REYNOLDS, op. cit., 2008.

5 Aversão essa que, curiosamente, ele compartilhava com Charles Darwin.

6 RICHARDS, op. cit., 2008, p. 29.

7 BREIDBACH, op. cit., 2006, p. 77.

8 USCHMANN, G. Ernst Haeckel. In: GILLISPIE, C. C. (ed.). Dicionário de biografias científicas. Editor da versão brasileira: Cesar Benjamin. Rio de Janeiro: Contraponto, 2007, p. 1050, v. 2.

$9 \quad$ Idem.

10 USCHMANN, op. cit., 2007, p. 1052.

11 ARCHIBALD, J. David. Edward Hitchcock's pre-darwinian (1840) "Tree of Life". Journal of the History of Biology, v. 42, p. 561-592, 2009.

12 REYNOLDS, A; HÜLSMANN, N. Ernst Haeckel's Discovery of Magosphaeraplanula: A Vestige of Metazoan Origins? History \& Philosophy of the Life Sciences, v. 30, p. 339-386, 2008.

13 RICHARDS, op. cit., 2008, p. 2.

14 ARCHIBALD, op. cit., 2009

15 RICHARDS, op. cit., 2008.

16 HAECKEL, Ernst. Natürliche Schöpfungsgeschichte. Berlin: Georg Reimer, 1868.

17 Essa expressão de indignação foi retomada por Stephen Jay Gould em 2000 para reafirmar as acusações de fraude em seu artigo "Abscheulich! (Atrocious!). Haeckel's distortions did not help Darwin", publicado em Natural History, v. 109, p. 42-49, 2000.

18 HAECKEL, E. Anthropogenie; oder, Entwickelungsgeschichte des menschen. Keimes und stammesgeschichte. Leipzig: Wilhelm Engelmann, 1891, p. 861-862.

19 WEINDLING, P. Genetics, eugenics, and the Holocaust. In: ALEXANDER, D. R.; NUMBERS, R. L. (Ed.) Biology and ideology: from Descartes to Dawkins. Chicago: The University of Chicago Press, 2010, p. 192-214.

20 LARSON, E. J. Biology and the emergence of the Anglo-American eugenics movement. In ALEXANDER, D. R.; NUMBERS, R. L. (Eds.) Biology and ideology: from Descartes to Dawkins. Chicago: The University of Chicago Press, 2010, p. 165-191.

21 RICHARDS, op.cit., 2008, p. 504.

22 BREIDBACH, op. cit., 2006, p. 199.

23 BREIDBACH. op. cit., 2006, p. 200

24 MARTINS, Lilian Al-Chueyr Pereira. A História da Ciência e o ensino da Biologia. Ciência \& Ensino, v. 5, p. 18-21, 1998

25 CARNeIRO, M. H. S.; GASTAL, M. L. História e Filosofia das Ciências no ensino de Biologia. Ciência \& Educação, v. 11, n. 1, p. 33-39, 2005.

26 ROSA, Sandra Regina Gimenez; SILVA, Marcos Rodrigues. A História da Ciência nos livros didáticos de Biologia do Ensino Médio. In: SIMPÓSIO NACIONAL DE ENSINO DE CIÊNCIA E TECNOLOGIA, 2., 2010.

27 BITTENCOURT, Fabricio Barbosa. 0 tratamento dado à história da biologia nos livros didáticos brasileiros recomendados pelo PNLEM-2007: análise das contribuições de Gregor Mendel. 2013. Dissertação (Mestrado em Ensino de Ciências, modalidade Ensino de Biologia) - Instituto de Física, Instituto de Química, Instituto de Biociências e Faculdade de Educação, Universidade de São Paulo.

28 ALFONSO-GOLDFARB, A. M. O que é história da Ciência. São Paulo: Brasiliense, 1994, p. 88-89.

29 MATTHEWS, M. R. Science teaching: the role of history and philosophy of science. New York: Routledge, 1994, p. 50. 
LIN, C.; CHENG, J.; CHANG, W. Making Science Vivid: Using a historical episodes map. International Journal of Science Education, v. 32, n. 18, p. 25212531, 2010.

31 ALLCHIN, D. Pseudohistory and Pseudoscience. Science \& Education, v. 13, p. 179-195, 2004.

32 LEITE, L. History of Science in Science education: development and validation of a checklist for analyzing the historical content of science textbooks. Science and Education, v.11, n. 2, p. 333-359, 2002. MARTINS, R. de A. Sobre o papel da história da ciência no ensino. In: BOLETIM DA SOCIEDADE BRASILEIRA DE HISTÓRIA DA CIÊNCIA, n. 9, p. 3-7, 1990. ROSA; SILVA, op. cit., 2010, p. 3.

35 BRASIL. Ministério da Educação. Secretaria de Educação Média e Tecnológica (Semtec). PCN - Parâmetros Curriculares Nacionais para o Ensino médio. BRASÍLIA: MEC/SEMTEC, 1999, p. 219.

36 BRASIL. Ministério da Educação. op. cit., 2010, p. 25.

37 BRASIL. Ministério da Educação. Secretaria de Educação Básica. Guia de livros didáticos: PNLD 2012: Biologia. Brasília: MEC/SEB, 2011.

38 BRASIL. Ministério da Educação, op. cit., 2011, p. 27-75.

39 LOPES, Sonia; ROSSO, Sérgio. Bio. São Paulo: Saraiva, 2010.

40 JÚNIOR, César da Silva; SASSON, Sezar; CALDINI JÚNIOR, Nelson. Biologia. São Paulo: Saraiva, 2010.

41 PEZZI, Antônio; GOWDAK, Demétrio; MATTOS, Neide de Simões. Biologia. São Paulo: FTD, 2010.

42 MENDONÇA, V.; LAURENCE, J. Biologia Para A Nova Geração. São Paulo: Nova Geração, 2010.

43 MARTHO, G. R.; AMABIS, J. M. Biologia. São Paulo: Moderna, 2010.

44 LINHARES, S. V.; GEWANDSNAJDER, F. Biologia Hoje. São Paulo: Ática, 2008.

45 BIZZO, N. M. V. Novas Bases da Biologia. São Paulo: Ática, 2010.

46 CHACON, V. Ser Protagonista - Biologia. São Paulo: Edições SM, 2010.

47 BARDIN, L. Análise de Conteúdo. Lisboa: Edições 70, 2009.

48 BITTENCOURT, op. cit., 2013.

49 BARDIN, op. cit., 2009, p. 121.

50 BARDIN, cit., 2009, p. 127.

510 protocolo desenvolvido por Bittencourt é uma adaptação do protocolo proposto originalmente por Leite, op. cit., 2002.

52 BITTENCOURT, op. cit., 2007, p. 50.

53 CARNEIRO; GASTAL, op. cit., 2005.

54 MARTINS, op. cit., 1998.

55 BARDIN, op. cit., 2009, p. 147.

56 LOPES; ROSSO, op. cit., 2010, p. 32.

57 HAECKEL, Ernst. Generelle Morphologie der Organismen. Berlin: Georg Reimer, 1866, p. 8.

58 MENDONÇA, V.; LAURENCE, J. Biologia Para A Nova Geração. Editora Nova Geração, 2010, p. 233.

59 REYNOLDS, op. cit., 2008, p. 5.

60 BRASIL. Ministério da Educação. Secretaria de Educação Básica. Guia de livros didáticos: PNLD 2012: Biologia. Brasília: MEC/SEB, 2011 , p. 9.

61 Idem.

62 LEITE, op. cit., 2002.

[Recebido em Dezembro de 2013. Aprovado para publicação em Setembro de 2014]. 